\title{
Validating Nine Clear Sky Radiation Models in Australia
}

\author{
N. A. Engerer ${ }^{a, b, 1, *}$, F. P. Mills $s^{a, c, d}$ \\ ${ }^{a}$ Fenner School of Environment and Society, The Australian National University, Forestry \\ Building 48, Linnaeus Way, Canberra, ACT 0200, Australia \\ ${ }^{b}$ National ICT Australia, Canberra Research Laboratory, Canberra, Australia \\ ${ }^{c}$ Research School of Physics and Engineering, ANU, Canberra, Australia \\ ${ }^{d}$ Space Science Institute, Boulder, CO, USA
}

\begin{abstract}
There have been many validation studies of clear sky solar radiation models, however, to date, no such analysis has been completed for Australia. Clear sky models are essential for estimating the generation potential of various solar energy technologies, the basic calibration of radiation measuring equipment, quality control of solar radiation datasets, engineering design (e.g. heating and cooling of buildings) and in agricultural and biological sciences (e.g. forestry). All of these areas are of considerable interest to the Australian economy and will benefit from an assessment of clear sky radiation models. With the recent provision of one-minute interval radiation data by the Australian Bureau of Meteorology for 20 sites across Australia, such a study can now be undertaken at a level not previously possible. Using up to ten years of data from each of 14 of these sites, clear sky periods are extracted through an automated detection algorithm. With these clear sky periods identified, nine of the most prominent beam and global clear sky radiation models are assessed using the relative Mean Bias Error, relative Root Mean Square Error and Coefficient of Determination as metrics. Further testing assessed model performance as a function of solar zenith angle and apparent solar time. Results show that for global clear sky simulations, the Solis, Esra and REST2 approaches perform best, while the Iqbal, Esra and REST2 methods are the most proficient clear sky beam models.
\end{abstract}

Keywords: $\quad$ solar energy, radiation, clear sky, modeling

\section{Introduction}

A "clear sky model" is a grouping of formulae that are capable of producing an estimate of the solar irradiance arriving at the Earth's surface. They may produce estimates of the individual beam $\left(E_{b n c}\right.$ clear sky direct normal

\footnotetext{
*Corresponding author. Tel +6126125 1658

Email address: nicholas.engerer@anu.edu.au (N. A. Engerer)

$U R L:$ http://nickengerer.org (N. A. Engerer)
} 
irradiance) or diffuse components of clear sky radiation (e.g. $E_{d h c}$ clear sky diffuse horizontal irradiance), or they may produce a global estimate ( $E_{g h c}$ clear sky global horizontal irradiance). A global estimate is often generated by an aggregation of the estimates from beam and diffuse models, but the estimate can occasionally be produced directly. Although these models most often produce broadband outputs, they must be capable of accounting for the scattering, reflection and absorption that occurs within given spectral bands, due to atmospheric constituents such as water vapor, ozone, aerosols (etc.), and atmospheric processes such as turbidity. There is great variance in the methods by which individual models account for these influences, with some models using only one input variable, with others requiring several. Many models are locally tuned or based on arbitrary coefficients, and thus there may be significant variations in their performance for different locations.

At the most basic level, clear sky models are used for the design of solar energy systems, as they correspond with a modeled device's optimal power output. These models are also similarly used in the design of the heating and cooling systems of buildings [22], as well as input to agricultural models [16, 52] and in the validation of dynamic meteorological models [11]. Specifically within the field of solar energy, clear sky radiation models are paramount to most modern analyses. An accurate clear sky estimate is very important for computing several of the various forms of radiation clear sky index (e.g. $\left.K_{c} ; K_{b}\right)$, which are the basis for normalizing solar radiation time series. This normalization is necessary in order to undertake more in-depth analyses (e.g. wavelets [35], variability [53], extracting cloud characteristics [8]) as well as forecasting its future characteristics $[24,54]$ and thus emphasis on its accuracy cannot be overstated. In a similar fashion, clear sky radiation models have been used as inputs to photovoltaic (PV) modeling routines, in order to calculate a clear sky index for PV, making it possible to extend such analyses to PV data time series [13]. Clear sky models are also used in the retrieval of radiation characteristics from satellite imagery [27] and to create clear sky data sets for testing radiation separation models (e.g. [12]). Hence, a well validated study, even for a particular region, will be quite useful.

\subsection{Previous Validation Studies}

Validation studies of many of these models have been completed, however no such study has been completed in manner specific to Australia. With the aim of completing such a study, it is important to review previous validation studies to identify the most commonly tested and best performing models.

Validation of clear sky radiation models has been around for over four decades (e.g Atwater and Ball [4]). While there have been many validations that examined a single model, (e.g. Louche et al. [40], Alam [2], Rigollier et al. [49]), this review will focus on those testing several models. In reviewing and comparing the performance of the available validation studies, several factors are of interest. One must note the resolution and geospatial distribution of data, the methodology for identifying clear sky periods for validation, the metrics used 
to assess model performance, and, of course, which models were validated and which performed best.

An early study is Gueymard [17], wherein 11 clear sky models were validated against both theoretical and measured values of hourly irradiance from seven sites from North America, Europe and Asia. Clear sky periods were extracted through "careful screening", with no explicit methodology provided. Models were evaluated using Mean Bias Error (MBE) and Root Mean Square Error (RMSE). Of these 11 models, four had RMSE below $6 \%$ and $9 \%$ for global and beam radiation, respectively, and were recommended for use in clear sky modeling: CPCR2 [16], Iqbal-C [31], EEC [45] and PSI [16] (descending order). Gueymard completed another, more in depth analysis of 18 models against 1-minute resolution data from five test sites from the Atmospheric Radiation Measurement (ARM) network, the National Renewable Energy Laboratory's (NREL) Baseline Solar Radiation Network (BSRN) and one from Saudi Arabia [20]. The selected sites were described to represent widely different climates. Clear sky periods were extracted using an ensemble of methods, with a primary focus on the LongAckerman filter [38] with follow-up analysis of the diffuse/beam ratio and use of automated sky cover observations (discarding $>5 \%$ coverage). Evaluation of performance was completed using Mean Bias Difference (MBD) and Root Mean Square Difference (RMSD), which are equivalent in computation to MBE and RMSE but with a different name in consideration of possible systematic errors in instrumentation. In addition, an uncertainty measure of the $95 \%$ confidence level was included, which includes consideration of the standard deviation of the observed data. Of the models tested the five most highly ranked models were REST2 [19], Simplified Solis [28], Hoyt [23], Bird [7] and Iqbal-C (in descending order), each receiving MBD and RMSD of $4 \%$ and $5 \%$ or less for the beam radiation estimates.

Several notable studies of comparable size adopted a similar climatologically diverse focus. Ineichen [27] compared 8 "high performance" models against 16 data banks (14 North American; 2 European), using observations with time steps from 15 to 60 minutes. Clear sky periods were selected empirically by using a $90 \%$ threshold of the clear sky beam radiation as calculated using a simple air mass model, and then limiting the absolute difference in variability to $10 \%$. Evaluation of model performance was completed using MBD, RMSD and standard deviation (SD), with the analysis and conclusion broken into two categories. First a "simple" input variable category (e.g. requiring only Linke turbidity and aerosol optical depth), where the Esra [49] and Molineaux [42] models performed best with MBD of $5 \%$ and $1 \%$, respectively (RMSD of 28-29 $\mathrm{W} / \mathrm{m}^{\wedge} 2$ ) for beam radiation. And secondly, a complex category (e.g. requiring spectral radiation measurements), where the Solis model had the best performance with a MBD of $2 \%, 10 \%$ and $11 \%$ for beam, global and diffuse radiation, respectively.

Younes and Muneer [56] used hourly data from six measurement sites in Spain, India and the UK to test four models; MRM [44], Esra [49], Yang [55] and REST2 [19]. This study is also useful, as it compares nine different clear sky period extraction methods, including the Long and Ackerman [38] and Ineichen 
[27] methods. In an initial investigation, they found poor results for methods that use only cloud cover observations or sunshine factor, mixed results for the Long-Ackerman method (noting that they used hourly data and the author recommend sub-15 minute data), and the best results from the Ineichen method - choosing it for their study. After applying the Ineichen method, they evaluated models with six metrics: R, slope, MBE, RMSE, skewness and kurtosis. They concluded that the MRM model provided the most accurate performance, but with a significant caveat in that it requires local data to re-calibrate the model. The REST2 model closely followed and was concluded to be best choice once versatility was considered.

Most recently, Reno et al. [48] validated nine models ([1, 9, 21, 33, 28, 3, 19, 51] and Badescu [5] equation 19) using 10 minute resolution data from 30 sites across the United States. In this study, a novel and robust method for extracting clear sky periods is proposed, which compares a clear sky radiation model estimate against the observed data using five tests: a rolling mean, a max limit test, variability in line length, variance in line slope and deviation from line slope. This method is employed in the present study and is discussed in more detail in Section 3.2. Evaluation of the models was completed using MBE and RMSE. They concluded that the REST2 model [19] performed best with an RMSE of $4.7 \%$, which is in agreement with other studies [56,20]. A few other models were comparable (RMSE of $5.0 \%$ and $7.3 \%$ ) and also recommended for use (Ineichen-Perez [29]and Robledo [51], respectively).

Other studies that focused on more geospatially limited regions with similar climatologies deserve to be discussed briefly. Alam [2] performed an analysis of three models, including the REST2 model, at four sites in India, using hourly data restricted to non-monsoon conditions, concluding the REST2 model performed best with an RMSE of approximately 7\%. Badescu [5] validated five models $[49,46,33,1,9]$ for two Romanian sites, concluding that the regionally calibrated ABCG model [1] performed best, but noted that the other simpler models were comparable in performance. Badescu et al. [6] then examined 54 models in a study with the same two Romanian sites using a ranking system to classify the models into "worst", "bad", "good enough", "good" and "best" categories. It concluded that the Ineichen-Perez [29], Esra [49], REST2 [19] and METSTAT [41] models were the best performers (RMSE $9.94-10.2 \%$ at the Bucharest site). Another study [25], which used data from three sites in Israel, validated the ABCG model along with three others [30,34,36] and concluded the Kondratyev and Manolova [34] model performed best with a MBD of $5 \%$.

\subsection{Overview of the Present Study}

The next sections discuss the models and data used in this study, including the origin of the radiation measurements, quality control, identification of the clear sky periods (and thereby clear sky days), and the manner in which the input variables for the clear sky models were handled. Validation through several error metrics will then be provided and the performance results discussed. The results provide a basis on which to select the "best" model(s) for use within Australia. 


\section{Models Tested}

The models chosen range in capability from one parameter models to complex, multi-band models and cover both beam and global horizontal radiation. The selected models were also chosen based on their presence and repeated testing in prior studies providing the opportunity to compare our results with previous validations. Finally, only models which are easily implementable (open source, straightforward coding) were considered.

The models tested here are presented briefly, with the reader referred to their original study for more detailed descriptions and their full formulation. It is important to note that some of these models either provide only a global estimate, or only a beam estimate, but that the majority provide both beam and global estimates. The experiment was designed so that there are nine models in either the beam or global categories of models. This study omits direct testing of the diffuse estimates, which several of these models produce, as by testing both the beam and global measurements, the results of the diffuse model are implied. This is also the case in the majority of clear-sky model validation studies available in the literature.

\subsection{Kasten}

Kasten [32] is the earliest of the global clear sky radiation models tested herein. This model was one of the first to include altitude based corrections in order to capture the changes in atmospheric interactions that occur according to height. The Kasten model takes the form:

$$
E_{g h c}=0.84 * E_{e^{x t_{n}}} * \cos \left(\theta_{z}\right) * \exp (-0.027 * A M) *\left(f_{h 1}+f_{h 2} *\left(T_{L}-1\right)\right)
$$

Where $f_{h 1}$ and $f_{h 2}$ are coefficients based on altitude, $A M$ the air mass and $T_{L}$ the Linke turbidity. Additionally, $\theta_{z}$ represents the solar zenith angle, and $E_{\text {ext }}$ the normal component of extraterrestrial radiation. This notation will appear throughout the remainder of the manuscript.

\subsection{Ineichen}

Using 12 clear sky days in Geneva, Ineichen [26] developed a clear sky beam radiation model based solely on the air mass value (assuming a fixed Linke turbidity set equal to 3 ):

$$
E_{b n c}=E_{e x t_{n}} * \exp (-0.16-0.22 * A M)
$$

\subsection{Ineichen and Perez}

The clear sky models developed by Ineichen and Perez [29] for beam and global horizontal radiation are based on the approach taken by Ineichen's first model (Section 2.2). However, the new formulations include empirical adjustments $\left(b, a_{1}, a_{2}\right)$ to Kasten's altitude coefficients and incorporate turbidity via the Linke turbidity coefficient. The clear sky beam model appears as:

$$
E_{b n c}=b * E_{e t_{n}} * \exp \left(-0.09 * A M *\left(T_{L}-1\right)\right)
$$

and the global horizontal clear sky model:

$$
E_{g h c}=a_{1} * E_{e t_{n}} * \cos \left(\theta_{z}\right) * \exp \left(-a_{2} * A M\right) *\left(f_{h 1}+f_{h 2} *\left(T_{L}-1\right)\right)
$$




\subsection{Bird}

The clear sky model presented in Bird and Hulstrom [7] is one of the most well-known and widely used clear sky models in the literature [20] . Its required inputs include aerosol optical depth, water vapor and ozone abundances, in order to compute the transmittances due to uniform gases $\left(T_{U}\right)$, Rayleigh scattering $\left(T_{R}\right)$, ozone $\left(T_{O}\right)$, aerosol $\left(T_{A}\right)$ and water vapor $\left(T_{W}\right)$. It takes the form:

$$
\begin{gathered}
E_{b n c}=E_{\text {ext }} * 0.9662 * T_{A} * T_{W} * T_{U} * T_{O} * T_{R} \\
E_{d h c}=E_{\text {ext }} * \cos (\theta) * 0.79 * T_{O} * T_{U} * T_{W} * T_{A A} \\
*\left(0.5 *\left(1-T_{R}\right)+B_{A} *\left(1-T_{A S}\right)\right) /\left(1-A M+(A M)^{1.02}\right)
\end{gathered}
$$

where $B_{A}$ is the forward scattering ratio, $T_{A A}$ aerosol scattering and $T_{A S}=$ $T_{A} / T_{A A}$. Additionally, $E_{\text {ext }}$ denotes the horizontal component of extraterrestrial radiation. Global radiation is then computed as:

$$
E_{g h c}=\left(E_{b n c} * \cos \left(\theta_{z}\right)+E_{d h c}\right) /\left(1-R_{G} * R_{S}\right)
$$

where $R_{S}$ is sky albedo and $R_{G}$ ground albedo.

\subsection{Atwater and Ball}

The Atwater and Ball model [3] is a transmittance based model:

$$
E_{g h c}=E_{e x t_{n}} * \cos \left(\theta_{z}\right) * T_{R} T_{G} * T_{W} * T_{P} * f /\left(1-R_{A} * R_{G}\right)
$$

It includes transmittance calculations for the uniform gases $T_{G}$, Rayleigh scattering $T_{R}$, water vapor $T_{W}$, and the absorption and reflection of aerosols $T_{P}$. It also accounts for atmospheric albedo $R_{A}$ and ground albedo $R_{G}$. It requires input information about water vapor content and the aerosol optical depth.

\section{6. $M A C$}

The MAC model refers to the work detailed in Davies and McKay [10], which requires relative humidity, temperature inputs, ozone content and aerosol optical depth as inputs, in order to calculate transmittances for Rayleigh scattering $\left(T_{R}\right)$, ozone $\left(T_{O}\right)$, aerosol $\left(T_{A}\right)$ and water vapor $\left(a_{w}\right)$. It is capable of estimating both beam and global radiation under clear skies:

$$
\begin{gathered}
E_{b n c}=E_{e x t} *\left(T_{O} * T_{R}-a_{w}\right) * T_{A} \\
E_{g h c}=E_{b n c} * \cos \left(\theta_{z}\right)+E_{d_{R}}+E_{d_{A}}
\end{gathered}
$$

where $E_{d_{R}}$ and $E_{d_{A}}$ are the estimates of the diffuse radiation from Rayleigh and aerosol scattering. 


\subsection{Molineaux}

The Molineux model produces a beam radiation estimate and was first presented in Molineaux et al. [43]. It is an adaptation of the original Linke turbidity formulation [37] in a clear dry atmosphere, but with an adjustment for the uniform gases:

$$
\begin{gathered}
\left.E_{b n c}=E_{e x t} * \exp \left(-\triangle_{c d a} * T_{L} * A M\right)\right) \\
\triangle_{c d a}=0.124-0.0285 * \log (A M)
\end{gathered}
$$

where $c d a$ stands for "clear dry atmosphere".

\subsection{Simplified Solis}

The initial version of the Solis model was spectral in nature, required sparsely measured inputs and was expensive computationally. However, a simplified broadband version was developed by Ineichen [28] to accommodate circumstances in which such computations are not possible. This broadband model is capable of producing clear sky estimates for beam, global and diffuse radiation:

$$
\begin{gathered}
E_{b n c}=E_{\text {ext }}^{\prime} * \exp \left(-\tau_{b} / \cos \left(\theta_{z}\right)^{b}\right) \\
E_{g h c}=E_{\text {ext }}^{\prime} * \exp \left(-\tau_{g} / \cos \left(\theta_{z}\right)^{g}\right) * \cos \left(\theta_{z}\right) \\
E_{d h c}=E_{\text {ext }}^{\prime} * \exp \left(-\tau_{d} / \cos \left(\theta_{z}\right)^{d}\right)
\end{gathered}
$$

where $E_{e x t}^{\prime}, \tau_{b}, \tau_{g}, \tau_{d}$ are all dependent on the aerosol optical depth, while also requiring water vapor and atmospheric pressure as inputs.

\subsection{Esra}

The Esra model was developed for the European Solar Radiation Atlas and is presented in Rigollier et al. [49]. The model requires one major input, the Linke turbidity (at $\mathrm{AM}=2$ ), in order to calculate Linke turbidity transmittances $\left(T_{L}\right)$ and uses an air mass based parameterization for Rayleigh optical thickness $\left(\delta_{R}\right)$. The model produces estimates of clear sky beam and diffuse solar radiation:

$$
\begin{gathered}
E_{b n c}=E_{e x t_{n}} * \exp \left(-0.8662 * T_{L} * A M * \delta_{R}\right) \\
E_{d h c}=E_{\text {ext }} * T_{R d}\left(T_{L}\right) * F_{d}\left(\theta_{z}, T_{L}\right)
\end{gathered}
$$

where $T_{R d}$ represents the diffusion of air molecules as a function of Linke turbidity and $F_{d}$ is referred to as the "diffuse angular function" which accommodates the increased diffusion that occurs at increasing zenith angles (increasing AM). 


\subsection{Iqbal-C}

The Iqbal modeled tested here is the Iqbal-C version, first reported in Iqbal [31]. For the computation of clear sky beam radiation, it requires transmission estimates for Rayleigh scattering $\left(T_{R}\right)$, uniform gas $\left(T_{G}\right)$, ozone $\left(T_{O}\right)$, aerosols $\left(T_{A}\right)$ and water vapor $\left(T_{W}\right)$ :

$$
E_{b n c}=0.975 * E_{e x t_{n}} * T_{R} * T_{G} * T_{O} * T_{A} * T_{W}
$$

The global clear sky component can then be computed via:

$$
E_{g h c}=\left(E_{b n c} * \cos \left(\theta_{z}\right)+E_{d_{R}}+E_{d_{A}}\right) *\left(1 /\left(1-R_{g} * R_{a}\right)\right)
$$

where $E_{d_{R}}$ and $E_{d_{A}}$ are estimates of the diffuse radiation from Rayleigh and aerosol scattering and $R_{S}$ is the sky albedo and $R_{G}$ the ground albedo.

\subsection{REST2}

The REST2 model of Gueymard [19] is unique among the models tested here, in that it is separated into two bands representing the broadband components of two separate series of spectra. It incorporates transmission estimates for Rayleigh scattering $\left(T_{R_{i}}\right)$, uniform gas $\left(T_{G_{i}}\right)$, ozone $\left(T_{O_{i}}\right)$, nitrogen dioxide $\left(T_{N_{i}}\right)$ and water vapor $\left(T_{W_{i}}\right)$ absorption, and finally, aerosol extinction $\left(T_{A_{i}}\right)$, which are calculated separately for each of the two bands. The beam estimates for each band appear as:

$$
E_{b n c_{i}}=E_{e x t_{n i} *} T_{R_{i}} * T_{G_{i}} * T_{O_{i}} * T_{N_{i}} * T_{W_{i}} * T_{A_{i}}
$$

The diffuse clear sky estimate $\left(E_{d_{i}}\right)$ is broken into two components within each band, incorporating a double layer scattering approach. In the upper layer $\left(E_{d p_{i}}\right)$, Rayleigh scattering (including forward scattering functions $B_{A}$ and $\left.B_{R}\right)$, ozone and uniform gas absorption are estimated. For the bottom layer $\left(E_{d d_{i}}\right)$, aerosol, water vapor, and nitrogen dioxide absorption and, separately, aerosol scattering $\left(T_{a s i}\right)$, ground and sky albedo $\left(\rho_{G_{i}}, \rho_{S_{i}}\right)$ are used:

$$
\begin{aligned}
E_{d p_{i}}= & E_{e x t_{h i}} * T_{G_{i}} * T_{O_{i}} * T_{N_{i}} \\
& * T_{W_{i}}\left[B_{R_{i}} *\left(1-T_{R_{i}}\right) * T_{A_{i}}^{0.25}+B_{A} * F_{i} * T_{R_{i}} *\left(1-T_{a s i}^{0.25}\right)\right] \\
& E_{d d_{i}}=\rho_{G_{i} *} \rho_{S_{i}} *\left(E_{b n_{i}} * \cos \left(\theta_{z}\right)+E_{d p_{i}}\right) /\left(1-\rho_{G_{i}} * \rho_{S_{i}}\right)
\end{aligned}
$$

and the total diffuse radiation on a horizontal surface:

$$
E_{d h c}=E_{d p_{i}}+E_{d d_{i}}
$$




\section{Data and Methods}

The data used for model validation was obtained from the Australian Bureau of Meteorology's (BoM) 1-minute radiation dataset. The sites are professionally maintained by the BoM, with the $95 \%$ uncertainty limits constrained to within $3 \%$ or $15 \mathrm{~W} / \mathrm{m}^{2}$ (whichever is greater), with regular calibrations undertaken according to research level standards [14]. Detailed information about the equipment used by the BoM solar radiation network can be obtained by accessing the data portal webpage at http://reg.bom.gov.au/climate/reg/oneminsolar/index.shtml.

The 14 sites chosen for the validation are spread across the continent and represent all of the major climate regions of Australia, which are quite diverse Peel et al. [47]. The data periods selected are representative of all the available one minute resolution observations available at the time this study was initiated (early 2013). These sites, their station number, altitude, location, data range and climate classification are presented in Table 1. In addition to the quality control undertaken by the BoM, the standard quality control methodology (QCRad) of Long and Shi [39] was applied to the dataset before analysis.

\subsection{Atmospheric Data}

All tested radiation models require the solar zenith angle as input (Table 2 ). All but two also require input that describes atmospheric conditions. The greatest accuracy will be achieved if the atmospheric parameters are based on temporally and geographically coincident atmospheric observations. However, appropriate local observations are not available for most applications (particularly for those operating in real time). To simulate the most typical situation, we have the used standard data approximations or climatological values for the atmospheric parameters. These issues have also been discussed elsewhere (e.g. Ineichen [27]). As a result, the performance of the more advanced models (e.g. REST2) may not be as good as that reported in previous studies.

In the case of ozone, turbidity, aerosols and water vapor, monthly mean values were extracted from the SoDa dataset [50] and a polynomial fit was used to obtain a value for each day [27, 13]. Further approximations and/or simplifications are required in several instances. For precipitable water (required in the Bird, Iqbal, Atwater \& Ball and REST2 models), we compute an estimate using the dewpoint temperature as the primary input [15]. We set ground reflectivity, required in the Bird, Iqbal and REST2 models, to a constant of 0.3 which is the approximate global land surface average. The transmissivity of clouds was set to a value of 1.0 in the Atwater \& Ball model [3], and a standard atmospheric value of 0.0002 was used for $\mathrm{NO}_{2}$ in the REST2 model [18].

As the result of these choices, the reader should be aware, that without the high-level data required by some of the more advanced models (e.g. REST2), their performance may be reduced from that documented elsewhere in the literature. It is not uncommon for the climatological values of Linke turbidity, ozone, aerosol optical depth and water vapor to be used in clear sky radiation 


\begin{tabular}{|c|c|c|c|c|c|}
\hline Site Name & Adelaide & Alice Springs & Broome & Cape Grim & Cairns \\
\hline Station \# & 23034 & 15590 & 3003 & 91148 & 31011 \\
\hline Elevation (m) & 2 & 546 & 7 & 95 & 113 \\
\hline Latitude & -34.95 & -23.80 & -17.95 & -40.68 & -16.87 \\
\hline Longitude & 138.52 & 133.89 & 122.24 & 144.69 & 145.74 \\
\hline Data Start & Mar 2003 & Apr 2003 & Jan 2001 & Jan 2001 & Jan 2001 \\
\hline Data End & Dec 2011 & Dec 2011 & Dec 2011 & Dec 2011 & Mar 2004 \\
\hline Climate & $\mathrm{CSb}$ & BWh & $\mathrm{BSh}$ & $\mathrm{Cfb}$ & Af \\
\hline Site Name & Darwin & Kalgoorlie & Learmonth & Melbourne & Mildura \\
\hline Station \# & 14015 & 12038 & 5007 & 86282 & 76031 \\
\hline Elevation (m) & 30 & 365 & 5 & 2 & 50 \\
\hline Latitude & -12.44 & -30.78 & -22.24 & -16.87 & -34.24 \\
\hline Longitude & 130.89 & 121.45 & 114.10 & 145.75 & 142.09 \\
\hline Data Start & Jan 2001 & Sep 2002 & Oct 2002 & Jan 2001 & Jan 2001 \\
\hline Data End & Dec 2011 & June 2006 & Jun 2006 & Dec 2011 & Dec 2005 \\
\hline Climate & Aw & $\mathrm{BSk}$ & BWh & $\mathrm{Cfb}$ & $\mathrm{BSk}$ \\
\hline Site Name & Mt. Gambier & Rockhampton & Tennant & Wagga & \\
\hline Station \# & 26021 & 39083 & 15135 & 72150 & \\
\hline Elevation $(\mathbf{m})$ & 63 & 10 & 376 & 212 & \\
\hline Latitude & -37.75 & -23.38 & -19.64 & -35.16 & \\
\hline Longitude & 140.77 & 150.48 & 134.18 & 147.46 & \\
\hline Data Start & Jan 2001 & Jan 2001 & Jan 2001 & Jan 2001 & \\
\hline Data End & Feb 2006 & Dec 2011 & Jun 2006 & Dec 2011 & \\
\hline Climate & $\mathrm{CSb}$ & $\mathrm{Cfa}$ & $\mathrm{BSh}$ & $\mathrm{Cfa}$ & \\
\hline
\end{tabular}

Table 1: Site information for the 14 Bureau of Meteorology solar measurement stations providing the validation data. Climate classifications are based on Peel et al. [47]. 


\begin{tabular}{ccccccccccc}
\hline Model & $\theta_{z}$ & $T_{L}$ & $\beta$ & $w$ & $u_{O}$ & $u_{n}$ & $\rho_{g}$ & $P$ & $T$ & $T_{d p t}$ \\
\hline Kasten & $\bullet$ & & & & & & & & & \\
Ineichen & $\bullet$ & & & & & & & & & \\
fneichen \& Perez & $\bullet$ & $\bullet$ & & & & & & & & \\
fird & $\bullet$ & & $\bullet$ & $\bullet$ & $\bullet$ & & $\bullet$ & $\bullet$ & & $\bullet$ \\
Atwater \& Ball & $\bullet$ & & $\bullet$ & $\bullet$ & & & & $\bullet$ & & $\bullet$ \\
MAC & $\bullet$ & & $\bullet$ & & $\bullet$ & & $\bullet$ & $\bullet$ & $\bullet$ & $\bullet$ \\
Molineaux & $\bullet$ & $\bullet$ & & & & & & & & \\
Solis & $\bullet$ & & $\bullet$ & $\bullet$ & & & & $\bullet$ & & \\
Esra & $\bullet$ & $\bullet$ & & & & & & $\bullet$ & & \\
Iqbal & $\bullet$ & & $\bullet$ & & $\bullet$ & & $\bullet$ & & & $\bullet$ \\
REST2 & $\bullet$ & & $\bullet$ & $\bullet$ & $\bullet$ & $\bullet$ & $\bullet$ & $\bullet$ & & $\bullet$ \\
\hline
\end{tabular}

Table 2: Model inputs as provided to the models under consideration in this validation study. Inputs are: the zenith angle $\theta_{z}$, Linke Turbidity coefficient $T_{L}$, Angstrom Beta $\beta$, atmospheric water vapour $w$, atmospheric ozone content $u_{O}$, atmospheric nitrogen content $u_{n}$, ground reflectivity $\rho_{g}$, surface pressure $P$, ambient temperature $T$ and dewpoint temperature $T_{d p t}$.

modeling studies [e.g 27, 56]. The reader should also understand that there are significant variations possible in these input parameters within the monthly resolutions used. More accurate estimates can be obtained from other sources such as archived satellite data, or surface based spectral imaging. At this time, there are not presently any studies which quantify the differences between these approaches, and thus the impact of our assumptions is unknown. However, this modeling study emphasizes ease-of-use and real-time usability, for which the SoDa extracted climatological values are quite suitable.

\subsection{Clear Sky Detection}

As discussed in Section 1.1, there are a variety of approaches for extracting the clear sky periods from the observed radiation dataset, nine of which are reviewed in Younes and Muneer [56]. With the minute resolution data available, it assumed that clear sky extraction methods based on hourly data will be insufficient. This leaves three methods from which to chose: Long and Ackerman [38], Ineichen [27] or the newer approach in Reno et al. [48]. Upon review, we decided to use the Reno et al. [48] approach, as it was easily tunable to our one minute dataset, and appeared to be the most robust after initial testing.

In the applied approach, the measured radiation time series is compared to a modeled clear sky radiation time series. In the present study, the Esra clear sky beam model was used in accordance with the findings of its superior performance for 2011 beam radiation data at Wagga Wagga, Australia [13]. In order to be labeled as a clear sky period, each subinterval was required to meet the five criteria from Reno et al. [48]: running mean $(\bar{E})$, maximum value $\left(E_{\max }\right)$, line length $(L)$, slope variance $\left(\sigma_{s}\right)$ and maximum deviation in slope $\left(\Delta S_{\max }\right)$. These criterion were tested for 5 point (6 minute) intervals of data, 


\begin{tabular}{|c|c|c|c|c|}
\hline$E$ & $E_{\max }$ & $L$ & $\sigma_{s}$ & $\Delta S_{\max }$ \\
\hline \hline $\pm 100 \mathrm{~W} / \mathrm{m}^{2}$ & $\pm 75 \mathrm{~W} / \mathrm{m}^{2}$ & 6 & 0.2 & $8 \mathrm{~W} / \min$ \\
\hline
\end{tabular}

Table 3: Values set for the five clear sky criteria from Reno et al. [48]: running mean $(\bar{E})$, maximum value $\left(E_{\max }\right)$, line length $(L)$, slope variance $\left(\sigma_{s}\right)$ and maximum deviation in slope $\left(\Delta S_{\max }\right)$

with limits set as presented in Table 3. The measure radiation must be within these limits, as compared to the value calculated from the clear sky model.

In order to be classified as "clear", a given observation time-step was required to pass the clear sky detection tests for both the beam and global observations. Examples of clear sky identification results are presented in Figure 1. In order for admission into the validation process, a day must experience at least $90 \%$ clear-sky periods, in order to ensure that skies are truly free of cloud cover. This $90 \%$ threshold was selected according to the methods established by Reno et al. [48].

\subsection{Performance Metrics}

Clear sky estimates from each of the models were computed at all times in which clear sky periods were detected for each of the 14 sites. There are nine global radiation models and nine beam radiation models between the eleven outlined in Section 2, and for each, model estimates were compared to the measured radiation for each clear sky period instance using three error metrics. The first two, relative Mean Bias Error (rMBE) and Root Mean Square Error (rRMSE) were chosen based on their frequent use throughout many other validation studies (Section 1.1). Thus, using these allows the results to be directly comparable to those completed elsewhere. These are computed as:

$$
\begin{gathered}
r M B E=\frac{1}{n \bar{O}} \sum_{i=1}^{n}\left(P_{i}-O_{i}\right) \\
r R M S E=\frac{1}{\bar{O}} \sqrt{\frac{1}{n} \sum_{i=1}^{n}\left(P_{i}-O_{i}\right)^{2}}
\end{gathered}
$$

where $P_{i}$ is a given model estimate, $O_{i}$ is the observed value at time $i, n$ is the total number of observations and $\bar{O}$ is the mean over all data points. Note that we include the prefix " $\mathrm{r}$ " in these measures, as the reported error is relative to the mean value of the data tested. This is an equivalent computation to MBE and RMSE used in the studies previously reviewed, but many of those studies did not make this important distinction.

The third, the Coefficient of Determination (denoted here as $R$ ) has been added as an additional model evaluation tool. It is a direct expression of how well model estimates match observed values, with a value of 1.0 being a perfect correlation. It is evaluated as: 

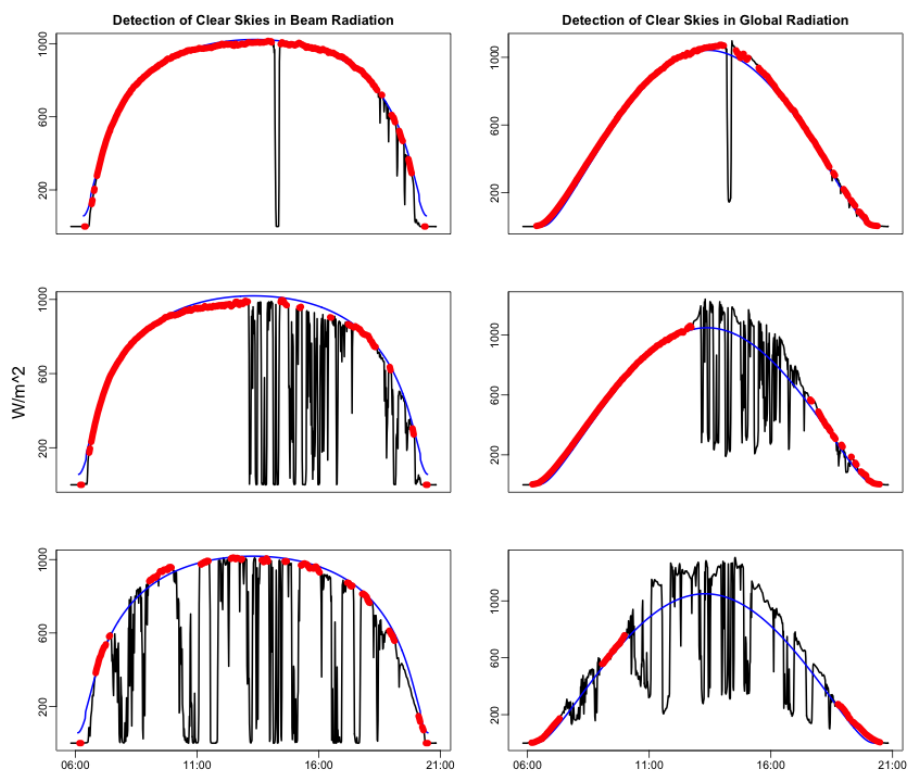

Figure 1: A collection of three days from January 2005 at Wagga Wagga, in which clear sky periods are identified automatically. Beam radiation at left, global radiation at right. The blue line is the clear sky model estimate (calculated by the Esra model), the black line is the measured radiation value and the red lines are the identified clear sky periods. Here, only the first day (top) would be included in the model validation process, as $90 \%$ of the daytime period was identified to be clear sky [48]. 


\begin{tabular}{|c|c|c|c|}
\hline & Global Radiation & Color Codes & \\
\hline Model Skill & rMBE & rRMSE & $\mathbf{R}$ \\
\hline Poor & $\geq 10 \%$ & $\geq 15 \%$ & $\leq 0.97$ \\
\hline Average & $\geq 5 \%,<10 \%$ & $\geq 10 \%,<15 \%$ & $\leq 0.98,>0.97$ \\
\hline Good & $0 \geq 2 \%,<5 \%$ & $0 \geq 5 \%,<10 \%$ & $0 \leq 0.99,>0.98$ \\
\hline Excellent & $<2 \%$ & $<5 \%$ & $>0.99$ \\
\hline
\end{tabular}

Table 4: The four performance categories for clear sky global radiation model estimates, color coded as reference to the results in Table 6

\begin{tabular}{|c|c|c|c|}
\hline & Beam Radiation & Color Codes & \\
\hline Model Skill & rMBE & rRMSE & $\mathbf{R}$ \\
\hline Poor & $\geq 10 \%$ & $\geq 15 \%$ & $\leq 0.80$ \\
\hline Average & $\geq 5 \%,<10 \%$ & $\geq 10 \%,<15 \%$ & $\leq 0.90,>0.80$ \\
\hline Good & $0 \geq 2 \%,<5 \%$ & $0 \geq 5 \%,<10 \%$ & $0 \leq 0.97,>0.90$ \\
\hline Excellent & $<2 \%$ & $<5 \%$ & $>0.97$ \\
\hline
\end{tabular}

Table 5: The four performance categories for clear sky beam radiation model estimates, color coded as reference to the results in Table 7

$$
R=1-\frac{\sum_{i=1}^{n}\left(O_{i}-P_{i}\right)^{2}}{\sum_{i=1}^{n}\left(O_{i}-\bar{O}\right)^{2}}
$$

In addition to computing these overall error measures for the models considered, we have developed categories under which model performance will be labeled "poor", "average", "good" and "excellent". This was motivated by the work of Badescu et al. [6], in which 54 clear sky radiation models were determined to be "good", "good enough" or "bad" through their rMBE and rRMSE values. "Good" models had $|\mathrm{rMBE}|<5 \%$ and $|\mathrm{rRMSE}|<15 \%$ while "bad" models had $|\mathrm{rMBE}|>10 \%$ and $|\mathrm{rRMSE}|>20 \%$. We have broken down our categories more finely, as the results from the models were often very close, and adjusted the bounds within which a model falls into these categories. These values can be found in Tables 4 and 5 for global and beam radiation, respectively.

\section{Global Clear Sky Validation Results}

A total of nine clear sky models for global radiation (Kasten, Ineichen-Perez, Atwater \& Ball, Bird, MAC, Solis, Esra, Iqbal, REST2) were tested for all clear sky periods for zenith angles $<85^{\circ}$ and the overall error metrics presented in Table 6 . We also provide plots of the correlation between observed and predicted global radiation at Melbourne in Figure 2, along with calculations of the rRMSE.

The results shown in Figure 2 suggest there are systematic biases in the tested models. A clear systematic negative bias is present in both the Atwater \& Ball and Iqbal models with the majority of plotted points appearing below the identity line. The Bird, MAC and Kasten models also display this bias, but 
to a lesser degree. rRMSE scores were lowest for the Ineichen-Perez, Esra and REST2 models and highest for the Atwater \& Ball, Iqbal and Bird models.

Table 6 reveals significant variation between sites in overall model performance. Relative error metrics tend to be highest in Cape Grim, Darwin and Melbourne and lowest in Alice Springs, Kalgoorlie and Tennant Creek, but the mean measured radiation is correspondingly lowest at the first three and highest at the second three. The absolute MBE and RMSE across all sites are more similar (in $W / m^{2}$ ).

Overall, the three most proficient models are the Ineichen-Perez, Solis and REST2 models, each of which had only one "average" score, with all the rest of them in the "good" or "excellent" categories. Each of the three poorest models, Kasten, Atwater and Iqbal reported at least one "poor" score, with very few to no "excellent" scores (Atwater). Although the Kasten model performed well at the Rockhampton site.

The Esra, MAC and Bird models fit nicely into a middle category of scoring consistently in the "good" category, each with a few instances of "average" and "excellent" scores and none in the "poor" category.

\subsection{Detailed Investigation of the 6 Best Models}

In order to understand which model is truly most proficient, we further investigate the performance of the six best models (Ineichen-Perez, Bird, MAC, Solis, Esra and REST2). Of particular interest is how the accuracy of the model estimates changes with zenith angle (e.g. Reno et al. [48]). To investigate this, we have grouped model estimates into $1^{\circ}$ zenith angle bins and computed the rRMSE for four locations with significantly different climatic zones: Alice Springs, Melbourne, Rockhampton and Wagga. The results are presented in Figure 3 .

At Alice Springs, the Ineichen-Perez model is consistently the most accurate model, being closely followed by the REST2, MAC and Esra models. There is no particularly poor performance for any of the models, but the Solis model does appear to lose accuracy at lower zenith angles while the remaining models improve. There is very close agreement across the models in the error experienced with rising zenith angle through approximately $80^{\circ}$. But at very high zenith angles, the Esra, Ineichen-Perez and REST2 models continue to climb in error, while the remaining models fall.

For Melbourne, the performance of the models is notably varied through different zenith angles. At low zenith angles, the low rRMSE values of the MAC, ESRA and Solis models are notable, as is the upward progression of error in the REST2 model with decreasing zenith angle. For angles greater than $40^{\circ}$, the accuracy of the Esra and MAC models worsens by 2-3\%, the REST2 model error falls and the Solis model remains consistent. All of the models tested begin a steep climb in rRMSE at zenith angles greater than $75^{\circ}$, reaching a peak at approximately $83^{\circ}$ before falling sharply again.

The rRMSE scores at low zenith angle behave differently at Rockhampton, with model accuracy being quite consistent from zenith angles of $10^{\circ}$ through 

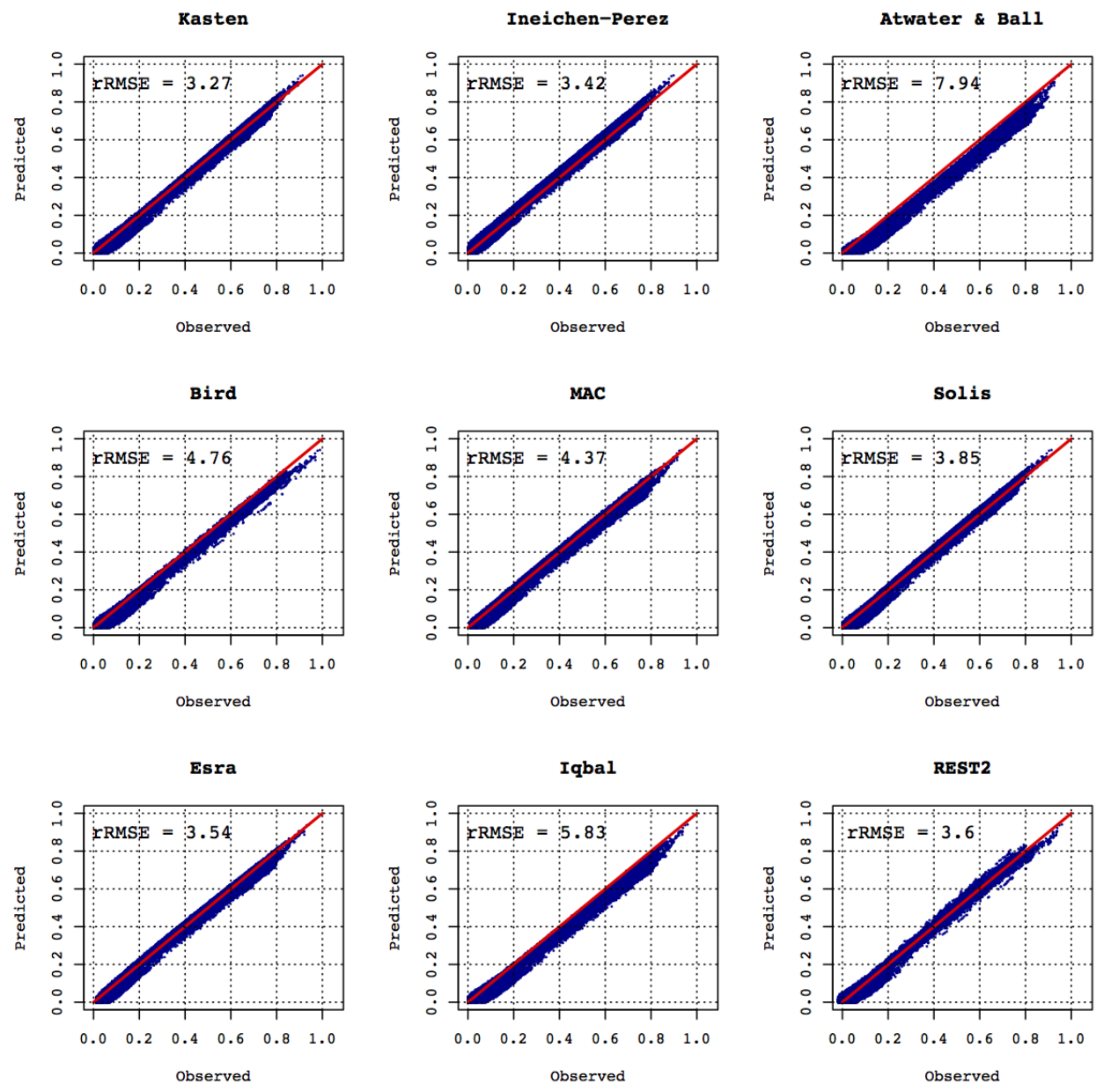

Figure 2: Predicted versus observed global radiation results for the nine global models tested at the Melbourne site (reported in $\mathrm{kW} / \mathrm{m}^{2}$ ), using a random selection of one-third of the available data. rRMSE (Root Mean Square Error) values are also reported for each of the models as a percentage. 
to approximately $75^{\circ}$, where once again the error climbs rapidly. The Esra, REST2 and Solis models display the most accurate and consistent performance in this range.

Whereas at Rockhampton it performed least well, the Bird model performs best at Wagga Wagga. It is closely followed by the MAC and Esra models. The REST2 model also does well, but only for zenith angles greater than $40^{\circ}$. The Ineichen-Perez model is a consistent under-performer, with particularly poor performance in the $60-80^{\circ}$ range.

These results are quite interesting for several reasons. First, there is clearly significant site-to-site variation amongst the models. Models which perform well in the overall error analysis, have significant problems at particular times of day. The Ineichen-Perez model is an excellent example. It has one of the best overall error results, but the zenith bin analysis reveals that at three of the sites (Melbourne, Rockhampton, Wagga Wagga) it consistently underperforms for zenith angles of $60-80^{\circ}$. Thus, while the overall analysis suggested the Ineichen-Perez, Solis and REST2 models are best, this more detailed analysis suggested the "best" models are Esra, Solis and REST2.

\subsection{Choosing the Best Model}

The final assessment we performed was to examine model performance as a function of the Apparent Solar Time (AST). To do so, we extracted two years worth (726 days) of days randomly from each of the 14 sites and computed the rMBE, rRMSE and $R$ scores for 15 minute bins of the AST. This allows the error to be analyzed in the context of solar time rather than the zenith angle, meaning the distribution of data points in each bin is more uniform and the sites, which have widely varying latitudes, are placed in a more directly comparable context. Within AST, a value of 12 is always solar noon. Values less than 12 are in the morning, greater than 12 in the afternoon/evening. The results are presented in Figure 4. The Solis model shows a positive bias for nearly all hours of the day, while the Esra model is consistently underpredicting clear sky radiation. The REST2 model over-predicts in the early hours of the morning, but quickly approaches a mean bias error near zero, before climbing again late in the day. The REST2 model has the least biased performance overall. The rRMSE scores are similar for all three models, but the REST2 model again does best with rRMSE scores reaching a minimum about solar noon. For the $R$ scores, we again observe similar performance among all three models, with slightly better correlations for the REST2 model.

\section{Beam Clear Sky Model Validation Results}

Again, a total of nine clear sky models (Ineichen, Ineichen-Perez, Bird, Molineaux, MAC, Solis, Esra, Iqbal and REST2) were tested, this time for beam radiation. Once again, we provide an analysis of the predicted versus observed data in Figure 5, using a random selection of one-third of the available data from the Melbourne site. It reveals much more varied results than those in the 

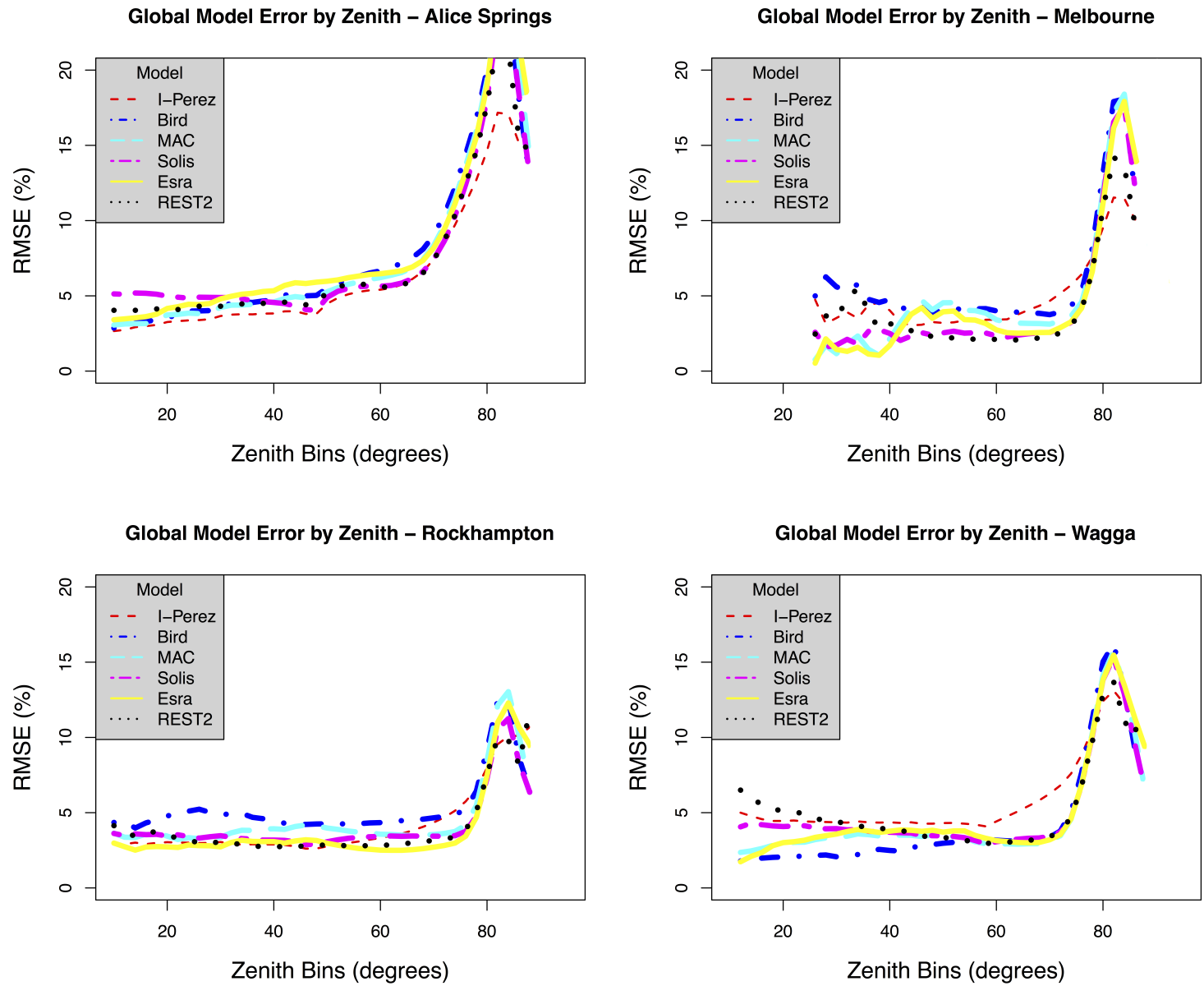

Figure 3: Relative Root Mean Square Errors (rRMSE) from the six most proficient global clear sky models (Ineichen-Perez, Bird, MAC, Solis, Esra and REST2) were computed for $1^{\circ}$ zenith angle bins and plotted against the zenith angle for the Alice Springs, Melbourne, Rockhampton and Wagga Wagga sites. 

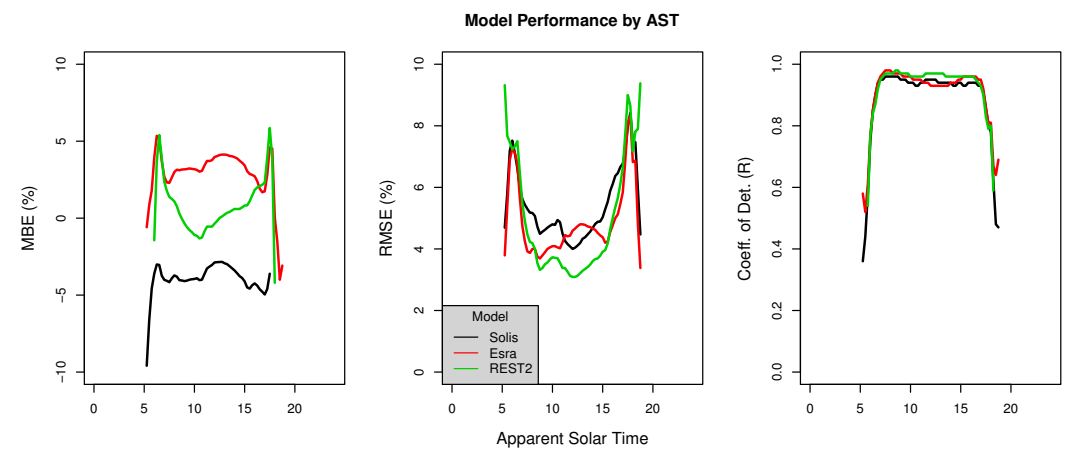

Figure 4: Performance measures for the three best global clear sky models, Solis, Esra and REST2 are plotted against Apparent Solar Time (AST). Models were evaluated by Mean Bias Error (rMBE), Root Mean Square Error (rRMSE) and the Coefficient of Determination (R), using a random selection of clear sky periods from all 14 Australian sites.

global radiation analysis. First, relatively large positive biases are apparent in the Ineichen, Ineichen-Perez and Molineaux models, with correspondingly high double digit rRMSE scores for Ineichen and Molineaux. The MAC, Esra and Bird models appear the most balanced in terms of their correlation, while the Iqbal, REST2 and Solis models are negative biased. The overall lowest rRMSE scores were received by the Bird, Esra and Solis models at 5.01\%, 5.51\% and $5.81 \%$ respectively.

The overall results are presented in Table 7 . Despite the more relaxed categories in the "excellent" through "poor" rankings, there is a clear increase in models achieving "poor" and "average" scores. This is attributable in part to the overall higher mean radiation observations, which are much higher in the case of the clear sky beam radiation periods since the pyrheliometer tracks the sun across the sky, recording a direct normal radiation value.

There are four models which perform well: Esra, Bird, Iqbal and REST2, each of which receives only 2 "average" scores, several "excellent" and none that are "poor". The Esra model displays a notable advantage over the other three models, with a majority of "excellent" scores and none that are less than "good". The poorest performers are the Ineichen and Molineaux models, which are the only beam models that do not have corresponding global or diffuse counterpart. The Ineichen-Perez, Solis and MAC models lie in between.

\subsection{Detailed Investigation of the 6 Best Models}

Following the approach in Section 4.1, the six best models (Ineichen-Perez, Bird, MAC, Esra, Iqbal and REST2) are observed as a function of solar zenith angle in Figure 6. There is much more variation in model performance among the four sites than was the case for the global radiation models. Alice Springs, 

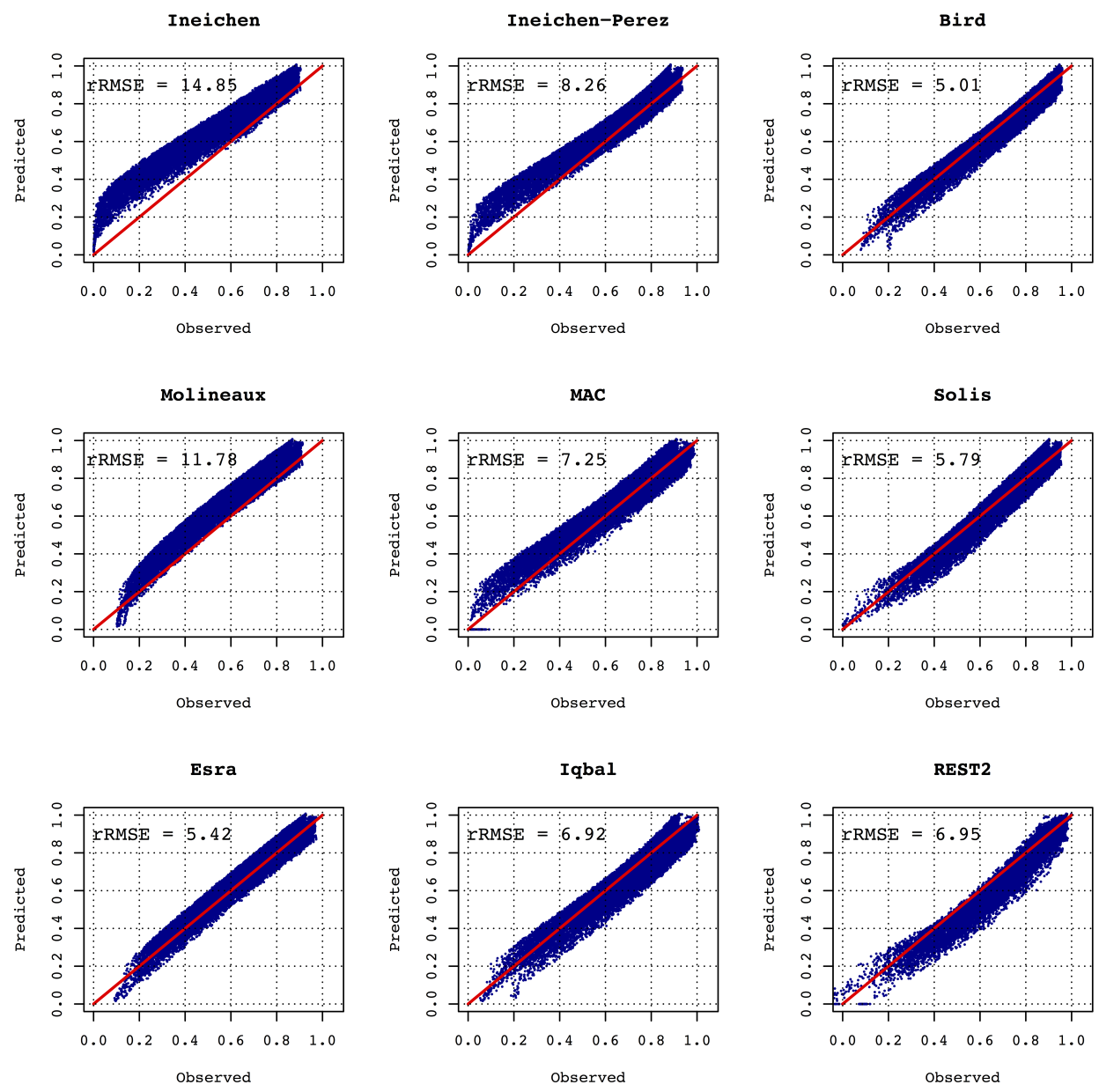

Figure 5: As in Figure 2, but for beam radiation. Predicted versus observed radiation results for the nine beam models tested at the Melbourne site (reported in $k W / m^{2}$ ), using a random selection of one-third of the available data. rRMSE (relative Root Mean Square Error) values are also reported for each of the models as a percentage. 
Rockhampton and Wagga Wagga have similar results, with steady model performance up to $60^{\circ}$. The Iqbal model appears best followed by the REST2, Bird and Esra models. At greater than $60^{\circ}$, model errors climb rapidly. In this region the Esra and Iqbal models provide the most consistent performance, with the Ineichen-Perez and REST2 models doing the least well. The performance of the Bird and MAC models is less consistent. Thus, the three best models are Iqbal, Esra and REST2, with the REST2 model chosen because of its accuracy at zenith angles up to $60^{\circ}$.

\subsection{Choosing the Best Model}

Once again, we extracted two years worth of days randomly from each of the 14 sites, computed the rMBE, rRMSE and $R$ scores for 15 minute bins of the Apparent Solar Time (AST), and present the results in Figure 7. The growth in error as one moves out from solar noon is much more rapid than in the global models. The Iqbal model displays a consistent positive bias, whereas the Esra model is most often underpredicting clear sky beam radiation. Both of these models approach a rMBE value of zero during mid-day. The REST2 model over-predicts beam radiation in the early/late hours of the day, before rapidly reducing its error until it is slightly negative at solar noon. This swing from positive to negative bias is perhaps the reason why it displays very small bias overall in the bulk error measures in Table 7 . All three models display a very similar pattern in rRMSE errors, with the Esra model performing best, reaching a nadir of approximately $4 \%$ near solar noon. Again, we observe large error values in the REST2 model in the early/later portions of the day. $R$ scores are particularly telling, with very poor correlations between predicted and measured radiation near mid-day for the Iqbal model and the Esra model having the strongest correlations at all times of the day.

\section{Conclusion}

By extracting clear sky periods from the radiation time series at 14 Australian measurement stations, we have been able to compare and rank nine global and nine beam clear sky models. First, bulk performance measures were calculated, by determining the overall relative Mean Bias Error, relative Root Mean Square Error and Coefficient of Determination for each model at each site. After classifying their performance as "excellent", "good", "average" and "poor", we determined which models generally perform the best/worst for each site. The six best were then subjected to additional testing, which identified the best three as the Solis, Esra and REST2 models. Of these, the REST2 model was found to have the lowest overall rMBE and rRMSE scores and the highest $R$ values, although its precision and accuracy varied strongly throughout the day. Consequently, we conclude that the REST2 model is the "best" model of those tested for global radiation, but that the Esra and Solis models offer comparable, and in some cases more reliable, performance. The relative computational simplicity of the Esra model could be considered a notable advantage. For the beam 

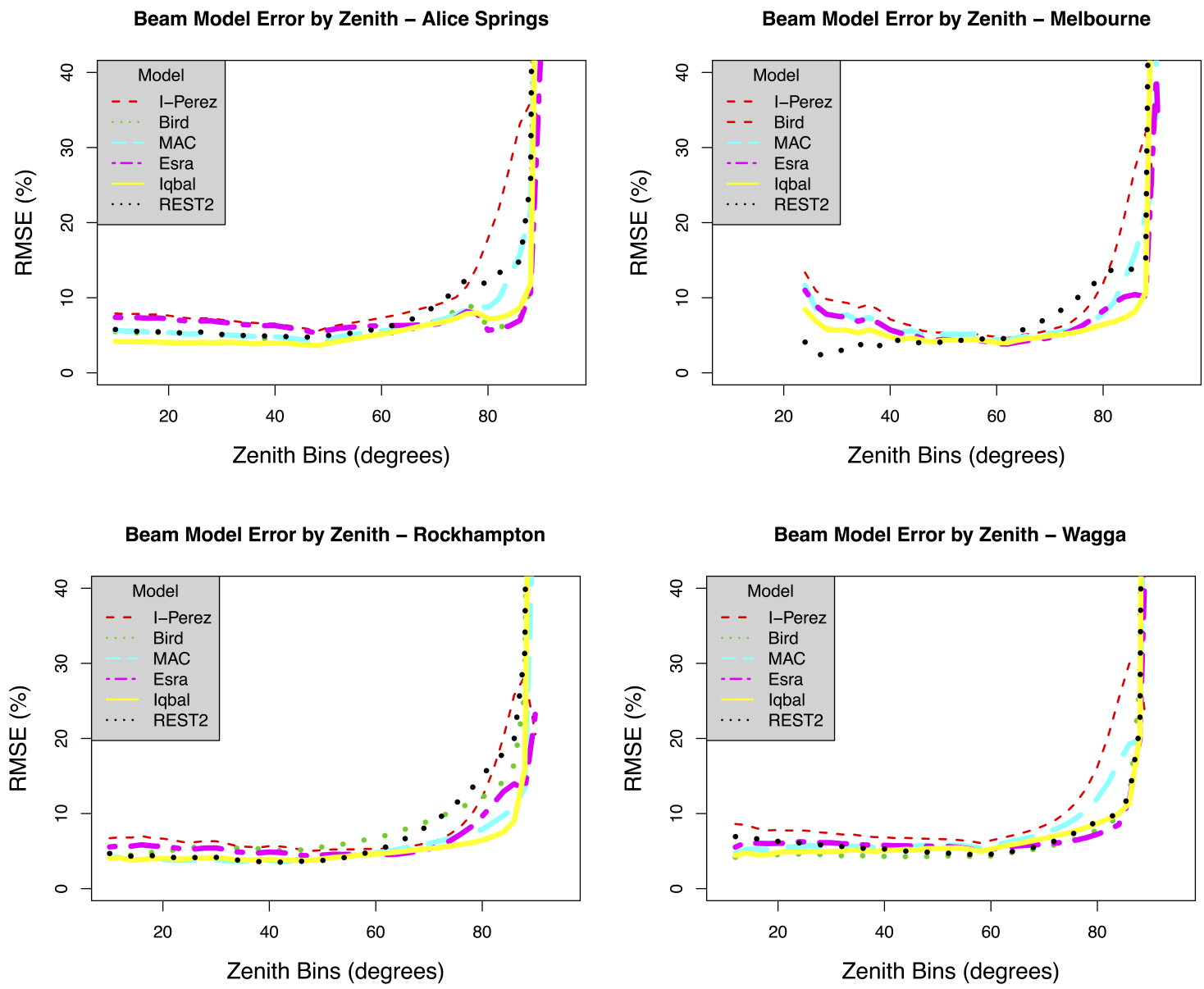

Figure 6: Root Mean Square Errors (rRMSE) from six of the most proficient beam clear sky models (Ineichen-Perez, Bird, MAC, Esra, Iqbal and REST2) were computed for $1^{\circ}$ zenith angle bins and plotted against the zenith angle for both the Alice Springs, Melbourne, Rockhampton and Wagga Wagga sites. 

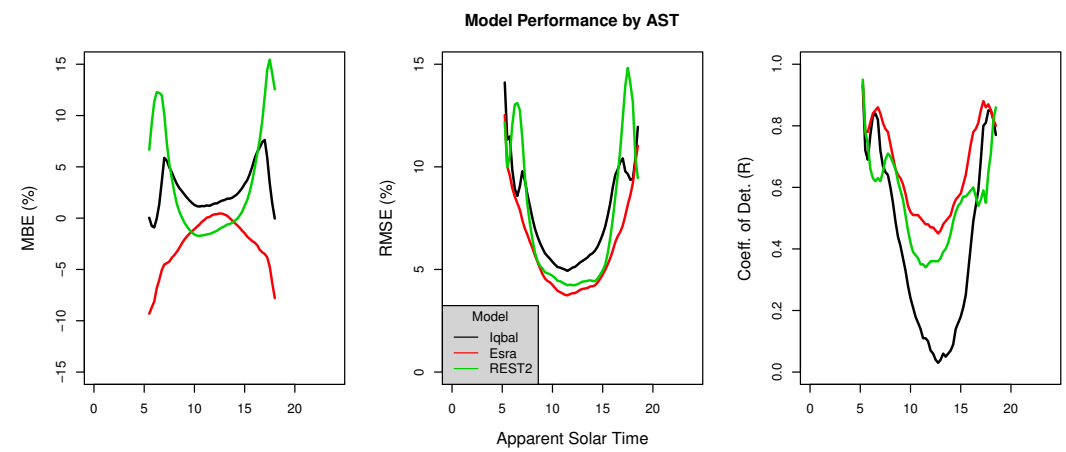

Figure 7: As in Figure 4, but for the three best beam clear sky models: Iqbal, Esra and REST2. Model error metrics are plotted against Apparent Solar Time (AST). Error metrics chosen were the Mean Bias Error (rMBE), Root Mean Square Error (rRMSE) and the Coefficient of Determination (R). This figure was built using a random selection of clear sky periods from all 14 Australian sites.

clear sky models, the same analysis was undertaken. The three best models were Solis, Esra and REST2. The REST2 model showed sharp swings in model bias and accuracy throughout the day and poor performance beyond $65^{\circ}$ (Figure 6). Iqbal model had very good rMBE and rRMSE scores, but demonstrated very significant problems with mid-day $R$ values. This leaves the Esra model as the clear choice for "best" beam model for estimating clear sky beam radiation in Australia. Summarily, the excellent performance of both the global and beam components of the Esra model, suggest that it should be considered the best overall clear sky modeling approach in the Australian context, with the REST2 model a clear second choice. These findings agree with other validation studies which have noted the proficiency of the Esra and REST2 models [56, 20, 48, 13]. It is important to note that this testing used sub-optimal inputs for many model parameters (e.g. nitrogen content is fixed, ozone depth is a climatological average, etc.) as we believe this reflects the context within which most of these models will be utilized. Therefore some of these models may have performed less favorably than expected (e.g. REST2). Future work should compare the results herein to those which use more accurate, higher resolution data. Of particular interest is the choice of this manuscript to use a fixed Linke turbidity across all zenith angles. This is likely the prime culprit behind the observed systematic decrease in accuracy with increasing zenith angles. Finally, we note that the beam radiation models performed worse than the global radiation models, which suggests there may be compensating problems in the diffuse components of the global models for the conditions we used in our tests. Future work should investigate these issues more fully. 


\section{Acknowledgements}

NAE would like to thank the United States National Science Foundation Graduate Research Fellowship Program and National ICT Australia, which provided partial support for this project. We thank the Australian Bureau of Meteorology and the Australian Renewable Energy Agency for supplying the high resolution (1 $\mathrm{min})$ radiation data.

\section{References}

[1] Adnot, J., Bourges, B., Campana, D., Gicquel, R., 1979. Utilisation des Courbes de Frequence Cumulees pour le Calcul des Installation Solaires. In Analise Statistique des Processus Meteorologiques Appliquee a L'nergie Solaire.

[2] Alam, S., Jul. 2006. Prediction of Direct and Global Solar Irradiance using Broadband Models: Validation of REST Model. Renewable Energy 31 (8), $1253-1263$.

[3] Atwater, M., Ball, J., 1981. Effects of Clouds on Insolation. Solar Energy $27,37-44$.

[4] Atwater, M. A., Ball, J. T., 1978. A numerical solar radiation model based on standard meteorological observations. Solar Energy 21, 163-170.

[5] Badescu, V., 1997. Verification of Some Very Simple Clear and Cloudy Sky Models to Evaluate Global Solar Irradiance. Solar Energy 61 (4), 251-264.

[6] Badescu, V., Gueymard, C. a., Cheval, S., Oprea, C., Baciu, M., Dumitrescu, A., Iacobescu, F., Milos, I., Rada, C., Jul. 2013. Accuracy Analysis for Fifty-Four Clear-Sky Solar Radiation Models Using Routine Hourly Global Irradiance Measurements in Romania. Renewable Energy 55, 85103.

[7] Bird, R., Hulstrom, R., 1981. A Simplified Clear Sky Model for Direct and Diffuse Insolation on Horizontal Surfaces. Tech. rep., Solar Energy Research Institute.

[8] Calbó, J., González, J., Pagès, D., 2001. A Method for Sky-Condition Classification from Ground-Based Solar Radiation Measurements. Journal of Applied Meteorology, 2193-2199.

[9] Daneshyar, M., Jan. 1978. Solar Radiation Statistics for Iran. Solar Energy 21 (4), 345-349.

[10] Davies, J., McKay, D., Jan. 1982. Estimating Solar Irradiance and Components. Solar Energy 29 (1), 55-64. 


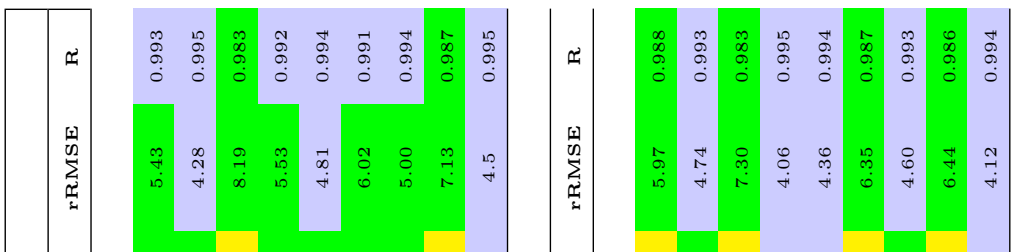

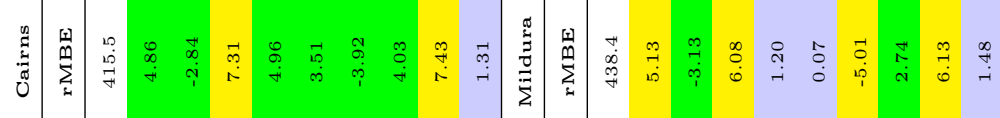

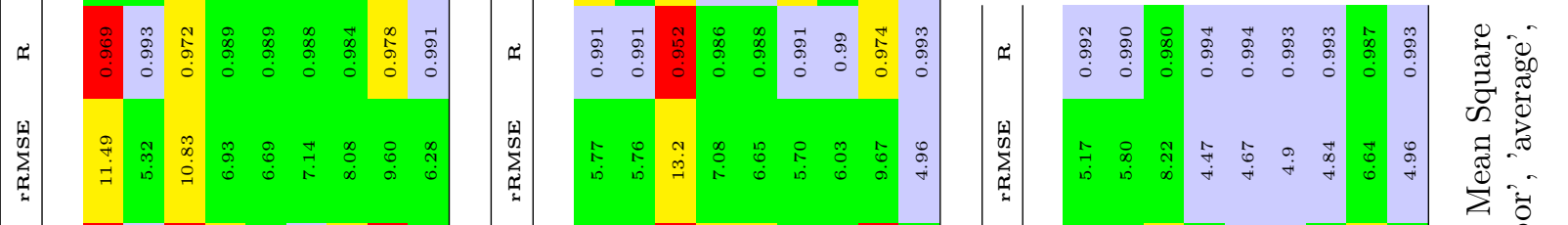

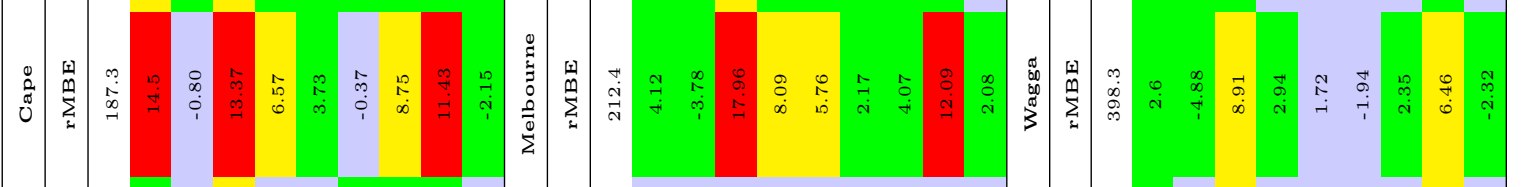

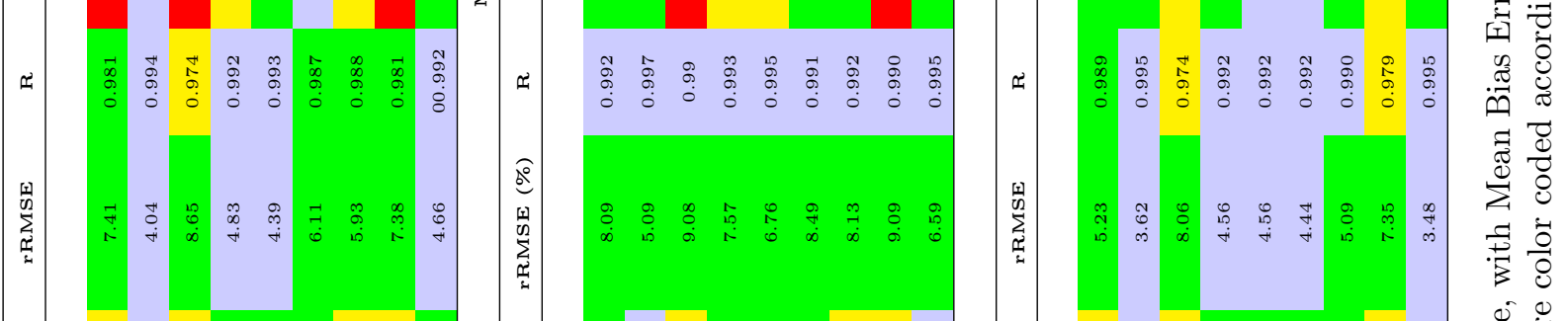

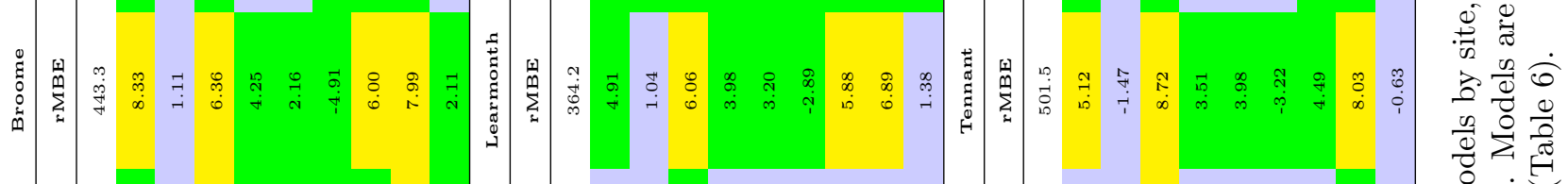

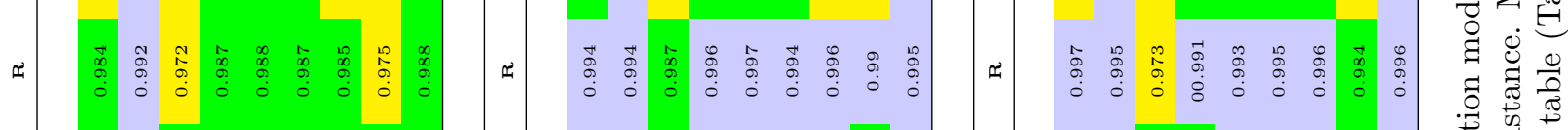

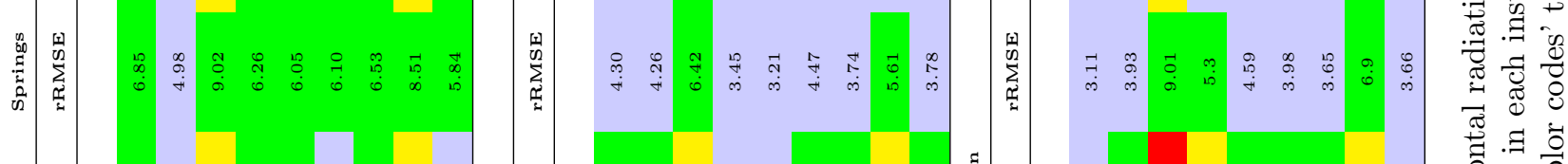

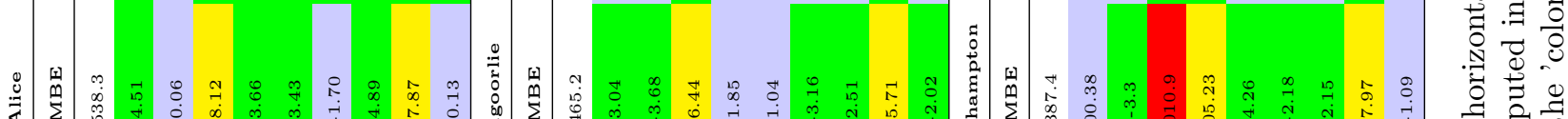

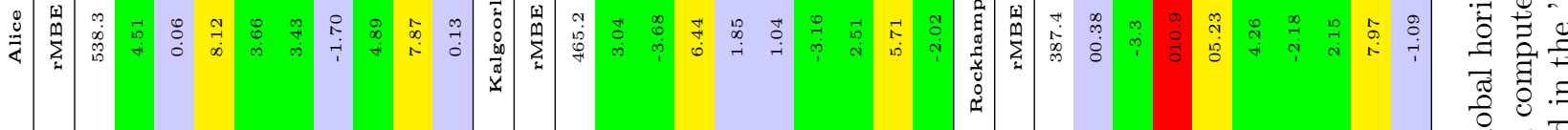

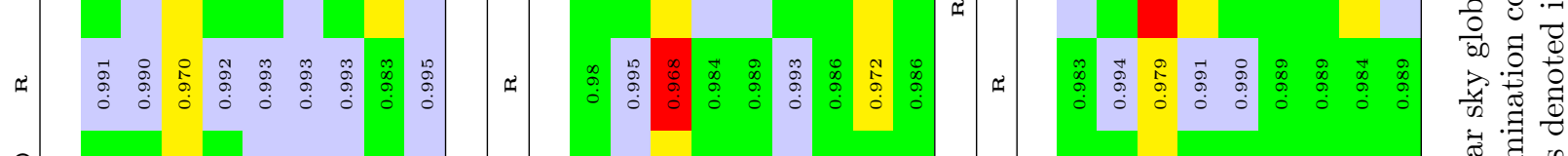

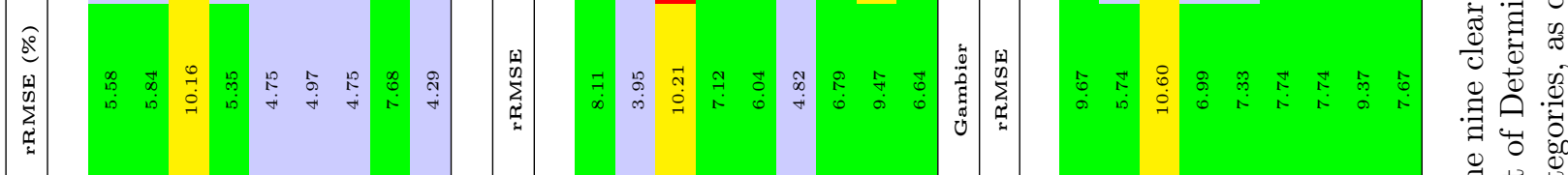

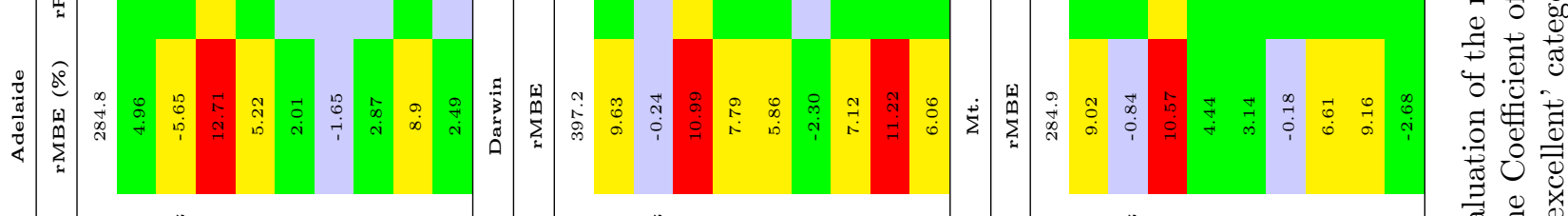

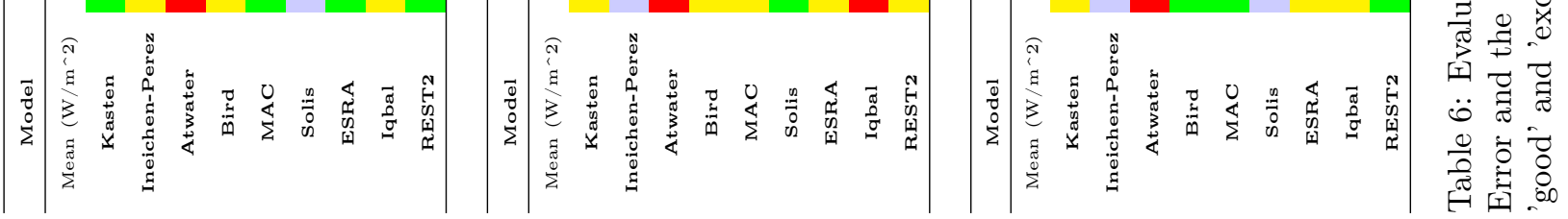




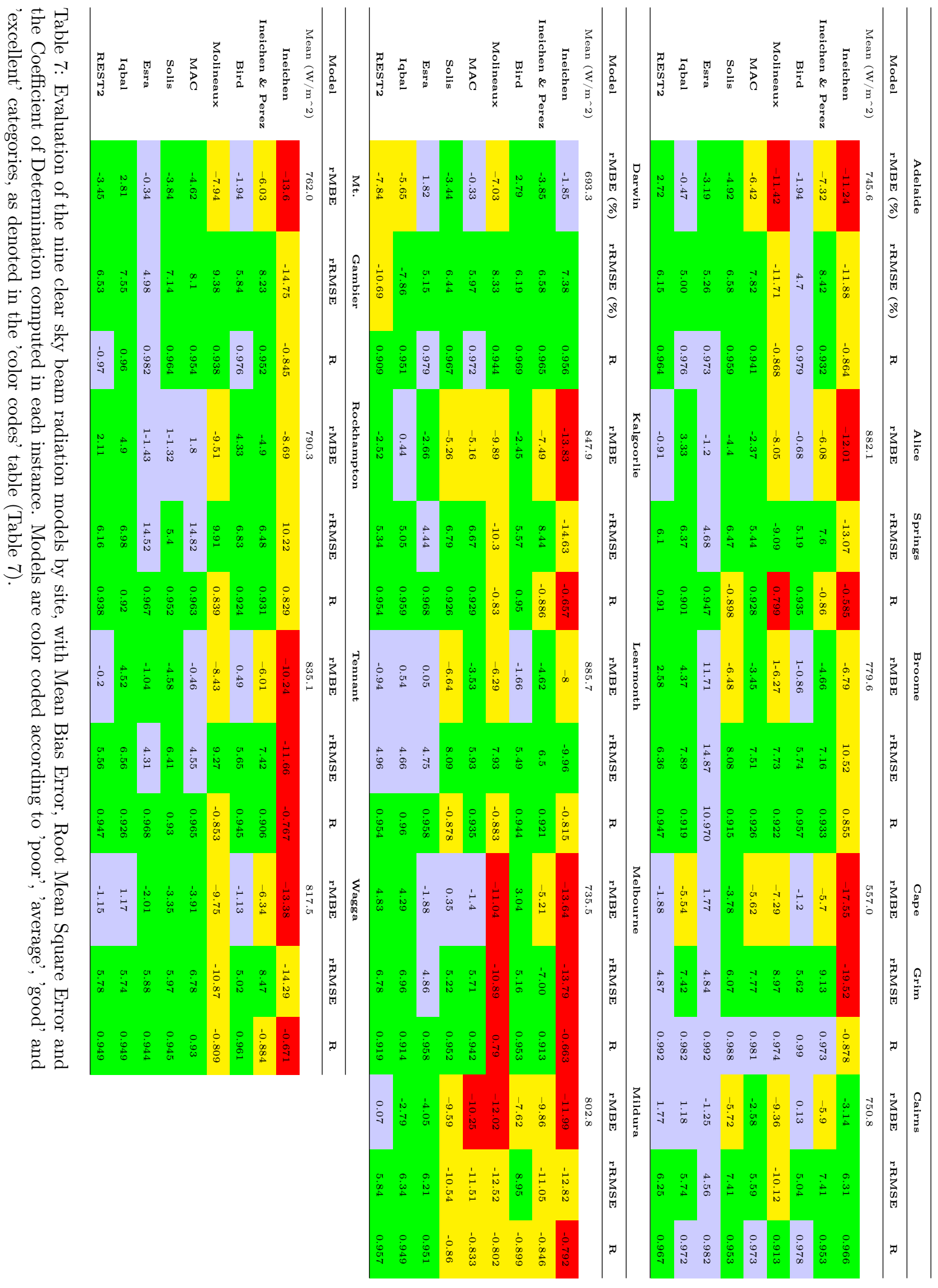




\begin{tabular}{cc}
\hline Major Notation & Explanation \\
\hline$E_{g h c}$ & Global horizontal clear sky radiation \\
$E_{b h c}$ & Beam horizontal clear sky radiation \\
$E_{d h c}$ & Diffuse horizontal clear sky radiation \\
$E_{\text {ext }}$ & Extraterrestrial normal radiation \\
$E_{\text {ext }}$ & Extraterrestrial horizontal radiation \\
$\theta_{z}$ & Solar zenith angle \\
$A M$ & Air mass \\
$T_{L}$ & Linke turbidity \\
$T_{U}$ & Uniform gases transmittance \\
$T_{R}$ & Rayleigh transmittance \\
$T_{O}$ & Ozone transmittance \\
$T_{A}$ & Aerosol transmittance \\
$T_{W}$ & Water vapor transmittance \\
$T_{N}$ & Nitrogen transmittance \\
$R_{S}$ & Sky albedo \\
$R_{G}$ & Ground albedo \\
$R_{S}$ & Atmosphere albedo \\
$\delta_{R}$ & Rayleigh optical thickness \\
\hline
\end{tabular}

Table 8: Major notation is provided, as a reference.

[11] Dehghan, A., Prasad, A. A., Sherwood, S. C., Kay, M., 2014. Evaluation and improvement of TAPM in estimating solar irradiance in Eastern Australia. Solar Energy 107, 668-680.

[12] Engerer, N. A., 2015. Minute Resolution Estimates of the Diffuse Fraction of Global Irradiance for Southeastern Australia. Solar Energy 116, 215-237.

[13] Engerer, N. A., Mills, F. P., 2014. KPV: A Clear-Sky Index for Photovoltaics. Solar Energy 105 (July), 679-693.

[14] Forgan, B., 1996. A New Method for Calibrating Reference and Field Pyranometers. Journal of Atmospheric and Oceanic Technology 13, 638-645.

[15] Garrison, J. D., 1992. Estimation of atmospheric precipitable water over Australia for application to the division of solar radiation into its direct and diffuse components. Solar Energy 48 (2), 89-96.

[16] Gueymard, C., 1989. An Atmospheric Transmittance Model for the Calculation of the Clear Sky Beam, Diffuse and Global Photosynthetically Active Radiation. Agricultural and Forest Meteorology 45, 215-229.

[17] Gueymard, C., 1993. Critical Analysis and Performance Assessment of Clear Sky Solar Irradiance Models Using Theoretical and Measured Data. Solar Energy 51 (2), 121-138. 
[18] Gueymard, C., 2003. Direct Solar Transmittance and Irradiance Predictions with Broadband Models. Part II : Validation with High-quality Measurements. Solar Energy 74, 381-395.

[19] Gueymard, C., Mar. 2008. REST2: High-Performance Solar Radiation Model for Cloudless-Sky irradiance, Illuminance, and Photosynthetically Active Radiation: Validation with a Benchmark Dataset. Solar Energy $82(3), 272-285$.

[20] Gueymard, C., Aug. 2012. Clear-Sky Irradiance Predictions for Solar Resource Mapping and Large-Scale Applications: Improved Validation Methodology and Detailed Performance Analysis of 18 Broadband Radiative Models. Solar Energy 86 (8), 2145-2169.

[21] Haurwitz, B., 1948. Insolation in Relation to Cloud Type. Journal of Meteorology.

[22] Hosobuchi, H., Yoshida, H., Uetani, Y., 2005. Calculation of the Heating and Cooling Load of Buidlings using a Sky Radiance Distribution Model. In: 9th International IBPSA Conference. No. 2. Montreal, pp. 427-434.

[23] Hoyt, D. V., Jan. 1978. A Model for the Calculation of Solar Global Insolation. Solar Energy 21 (1), 27-35.

[24] Huang, J., Korolkiewicz, M., Agrawal, M., Boland, J., Jan. 2013. Forecasting solar radiation on an hourly time scale using a Coupled AutoRegressive and Dynamical System (CARDS) model. Solar Energy 87, 136-149.

[25] Ianetz, A., Lyubansky, V., Setter, I., Kriheli, B., Evseev, E. G., Kudish, A. I., Jan. 2007. Inter-comparison of Different Models for Estimating Clear Sky Solar Global Radiation for the Negev Region of Israel. Energy Conversion and Management 48 (1), 259-268.

[26] Ineichen, P., 1983. Quatre Annees de Mesures D'ensoleiilement a Geneve. Ph.D. thesis, University of Geneva.

[27] Ineichen, P., Apr. 2006. Comparison of Eight Clear Sky Broadband Models Against 16 Independent Data Banks. Solar Energy 80 (4), 468-478.

[28] Ineichen, P., Aug. 2008. A Broadband Simplified Version of the Solis Clear Sky Model. Solar Energy 82 (8), 758-762.

[29] Ineichen, P., Perez, R., Sep. 2002. A New Airmass Independent Formulation for the Linke Turbidity Coefficient. Solar Energy 73 (3), 151-157.

[30] Iqbal, M., 1980. Prediction of Hourly Diffuse Solar Radiation from Measured Hourly Global Radiation on Horizontal Surface. Solar Energy 24, 491-503.

[31] Iqbal, M., 1983. An Introduction to Solar Radiation. Academic Press Inc., New York. 
[32] Kasten, F., 1984. Parametriesierung der Globalstrahlung durch Bedekungsgrad und Trubungsfaktor. Annalen dere Meteorologie Neue Folge 20, 49-50.

[33] Kasten, F., Czeplak, G., 1980. Solar and Terrestrial Radiation Dependent of the Amount and Type of Cloud. Solar energy 24, 177-189.

[34] Kondratyev, K., Manolova, M., 1960. The Radiation Balance of Slopes. Solar Energy 4 (1).

[35] Lave, M., Kleissl, J., Arias-Castro, E., Aug. 2011. High-frequency Irradiance Fluctuations and Geographic Smoothing. Solar Energy 86 (8), 21902199.

[36] Lingamgunta, C., Veziroglu, T., Jan. 2004. A Universal Relationship for Estimating Clear Sky Insolation. Energy Conversion and Management 45 (1), $27-52$.

[37] Linke, F., 1922. Transmissions-Koeffizient und Trubungsfaktor. Beitr. Phys. fr. Atmos. 10, 91-103.

[38] Long, C. N., Ackerman, T. P., Jun. 2000. Identification of clear skies from broadband pyranometer measurements and calculation of downwelling shortwave cloud effects. Journal of Geophysical Research 105 (D12), 15609.

[39] Long, C. N., Shi, Y., 2006. The QCRad Value Added Product : Surface Radiation Measurement Quality Control Testing, Including Climatology Configurable Limits. Tech. Rep. September, U.S. Department of Energy.

[40] Louche, A., Simonnot, G., Iqbal, M., Mermier, M., Jan. 1988. Experimental Verification of Some Clear-Sky Insolation Models. Solar Energy 41 (3), 273 279 .

[41] Maxwell, E., Apr. 1998. METSTAT- The solar radiation model used in the production of the National Solar Radiation Data Base (NSRDB). Solar Energy 62 (4), 263-279.

[42] Molineaux, B., Ineichen, P., 1996. On the Broadband Transmittance of Direct Irradiance in a Cloudless Sky and Its Applications to the Parameterization of Atmospheric Turbidity. Solar energy 56 (6), 553-563.

[43] Molineaux, B., Ineichen, P., Delaunay, J., 1995. Direct Luminous Efficacy and Atmospheric Turbidity - Improving Model Performance. Solar Energy $55(2), 125-137$.

[44] Muneer, T., Gul, M., Kambezedis, H., 1998. Evaulation of an All-sky Meteorological Radiation Model Against Long-term Measured Hourly Data. Energy conversion and management 39 (3), 303-317.

[45] Page, J., 1986. Prediction of Solar Radiation on Inclined Surfaces. D. Reidel Publishing Company. 
[46] Paltridge, G., Proctor, D., 1976. Monthly Mean Solar Radiation Statistics for Australia. Solar Energy 18 (3), 235-243.

[47] Peel, M. C., Finlayson, B. L., McMahon, T. A., 2007. Updated World Map of the Köppen-Geiger Climate Classification. Hydrology and Earth System Sciences 11 (5), 1633-1644.

[48] Reno, M., Hansen, C., Stein, J., 2012. Global Horizontal Irradiance Clear Sky Models: Implementation and Analysis. Tech. Rep. March, Sandia National Laboratories.

[49] Rigollier, C., Bauer, O., Wald, L., 2000. On the Clear Sky Model of the ESRA - European Solar Radiation Atlas - With Respect to the Heliostat Method. Solar Energy 68 (1), 33-48.

[50] Rigollier, C., Lefevre, M., Wald, L., 2001. Heliosat version 2. Integration and Exploitation of Networked Solar Radiation Databases for Environment Monitoring (SoDa Project). Tech. rep.

URL http://soda-is.com

[51] Robledo, L., Soler, A., 2000. Luminous Efficacy of Global Solar Radiation for Clear Skies. Energy Conversion and Management 41.

[52] Svendsen, H., Jensen, H., 1990. The Effect of Clear Sky Radiation on Crop Surface Temperature Determined by Thermal Thermometry. Agricultural and Forest Meteorology 50, 239-243.

[53] Woyte, A., Belmans, R., Nijs, J., Feb. 2007. Fluctuations in Instantaneous Clearness Index: Analysis and Statistics. Solar Energy 81 (2), 195-206.

[54] Yang, D., Jirutitijaroen, P., Walsh, W. M., Dec. 2012. Hourly Solar Irradiance Time Series Forecasting Using Cloud Cover Index. Solar Energy 86 (12), 3531-3543.

[55] Yang, K., Huang, G., Tamai, N., Jan. 2001. A Hybrid Model for Estimating Global Solar Radiation. Solar Energy 70 (1), 13-22.

[56] Younes, S., Muneer, T., Jun. 2007. Clear-sky Classification Procedures and Models using a World-wide Data-base. Applied Energy 84 (6), 623-645. 